\title{
Condom Use Trajectories in Adolescence and the Transition to Adulthood: The Role of Mother and Father Support
}

\author{
Emily S. Pingel and José A. Bauermeister \\ University of Michigan
}

Stevenson Fergus

Queen's University

\author{
Katherine S. Elkington \\ Columbia University and New York State Psychiatric \\ Institute
}

Cleopatra H. Caldwell and
Marc A. Zimmerman
University of Michigan

Few studies have investigated how mother and father support differ on predicting youths' sexual risk behavior. We therefore examined the influence of parental support on condom use trajectories and its correlates in a predominantly African-American sample ( $N=627 ; 53 \%$ female participants; $M=14.86$ years $[S D=0.64])$ from adolescence to young adulthood. We used hierarchical growth curve modeling to examine the relationship between condom use, substance use, psychological distress, and parental support prospectively. We found that consistent condom use decreased over time and was associated negatively with psychological distress and substance use. Furthermore, both maternal and paternal support were associated with more condom use over time. We discuss the implications of our findings for HIV prevention programs.

In the United States, African-American youth aged 15-24 years are disproportionately affected by the HIV epidemic and account for higher rates of sexually transmitted infections (STI) compared with White and Hispanic youth (Centers for Disease Control and Prevention [CDC], 2006, 2008). Higher rates of HIV or STI infection in African-American youth may be due to differences in the cumulative exposure to risk factors associated with condom use in adolescence and young adulthood, including family processes (Browning, Leventhal, \& BrooksGunn, 2005; Haveman \& Wolfe, 1994), youth psychological distress, and substance use (Fisher, Eke, Cance, Hawkins, \& Lam, 2008). Although these sexual risk correlates have been well documented (Marshall, Crepaz, \& O'Leary, 2010), few studies have examined how health promotive factors can offset risk and thereby alter condom use trajectories in African-American youth.

Scholars have underscored the need to integrate family processes into HIV prevention for youth (Donenberg, Paikoff, \& Pequegnat, 2006). Key family processes such as parental support have been

This research was supported by a NIDA grant (R01-DA07484; Principal Investigator: Marc A. Zimmerman) and a NIMH grant (K01 MH089832; Principal Investigator: Katherine S. Elkington).

Requests for reprints should be sent to José A. Bauermeister, School of Public Health, University of Michigan, 1415 Washington Heights, SPH I, Rm 3822, Ann Arbor, MI 48109-2029. E-mail: jbauerme@umich.edu associated with the healthy development of adolescents (Repetti, Taylor, \& Seeman, 2002) and young adults (Hair, Moore, Garrett, Ling, \& Cleveland, 2008). As parents often play a significant role in shaping the context in which youth learn about relationships and behavior (Perrino, GonzalezSoldevilla, Pantin, \& Szapocznik, 2000), it is important to determine whether and how particular maternal and paternal influences serve as promotive factors and diminish the effects of risk factors, such as substance use and psychological distress, among African-American youth across adolescence and the transition into young adulthood. These data may help inform developmentally appropriate sexual risk reduction programs for African-American youth (Marshall et al., 2010). As a contribution to these efforts, we sought to examine how both paternal and maternal support were associated with condom use among African-American youth over time. We assessed these relationships both during adolescence and young adulthood. Waves 2 through 4 correspond approximately to participants at ages 15-18; Waves 5 through 8 approximately correspond to participants from age 20-23. We omitted Wave 1 in this analysis because the parental support measure was not asked independently for mothers and fathers in Wave 1. In the

(C) 2012 The Authors

Journal of Research on Adolescence (C) 2012 Society for Research on Adolescence DOI: $10.1111 /$ j.1532-7795.2011.00775.x 
present study, we define parental support as the process by which parents or primary caregivers provide their children with encouragement, listen to them, help them solve problems, and share life concerns.

\section{Consistent Condom Use Among Youth as an HIV or STI Risk Reduction Strategy}

When used correctly and consistently, condoms are an effective barrier against the transmission of HIV and other STIs (Wingood \& DiClemente, 1996). Sexual behaviors adopted during adolescence and young adulthood may predict sexual practices later in the life course (Stiffman, Dore, Earls, \& Cunningham, 1992). Much of the youth sexual risk behavior literature, however, has focused either on adolescence (Bingham \& Crockett, 1996) or on young adulthood (Humblet, Paul, \& Dickson, 2003). The privileging of one developmental period over another limits our ability to understand how these life stages are interconnected, to identify critical moments when youths' sexual behaviors change, and to recognize key points of intervention. For some youth, condom use may decrease as a reflection of their shift toward monogamous relationships and/or childbearing, whereas for others, a decrease in consistent condom use may have greater risks of HIV or STIs infection if they report having multiple partners. To better understand sexual development over time, a study that examines changes in condom use across both adolescence and young adulthood over a lengthy period is necessary.

Changes in condom use patterns between adolescence and young adulthood may also differ by race (Fergus, Zimmerman, \& Caldwell, 2007). Unfortunately, most longitudinal studies of sexual risk behavior examining African-American youth exclusively have included only two or three waves of data (Crosby, DiClemente, Wingood, Lang, \& Harrington, 2003; O'Donnell, O'Donnell, \& Stueve, 2001; Tapert, Aarons, Sedlar, \& Brown, 2001), which cannot fully capture behavioral trajectories, and do not represent the developmental period when adolescents begin transitioning into adult roles. Consequently, understanding the developmental trajectories of sexual risk behaviors in African-American youth requires multiple waves of long-term longitudinal data. Our study provides an opportunity to examine condom use within each developmental period, adolescence and young adulthood, providing a rich understanding of changes experienced by African-American youth over time.

\section{Using a Resiliency Perspective to Explore Promotive Factors That Offset Sexual Risk}

The transition from adolescence to young adulthood may be a harbinger of a healthy and productive adult life for some youth, or it may presage adjustment problems (Arnett, 2000). Few researchers, however, have used a resiliency perspective to study the sexual behaviors of youth transitioning from adolescence to young adulthood. A resiliency perspective may help us understand consistent condom use patterns over time, by enriching our understanding of how risk and promotive factors influence consistent condom use among AfricanAmerican youth (Fergus \& Zimmerman, 2005).

Resiliency is defined as successful adaptation in the face of risk, providing a framework that directs attention to successful coping and adjustment despite risk exposure (Garmezy, 1991; Rutter, 1987). A resiliency perspective has received increasing attention over the last decade and has helped frame development using a strengths model rather than a deficit and problem-oriented approach (Fergus \& Zimmerman, 2005; Luthar, 2003). Compared to the number of studies that focus on risk factors, such as substance use and psychological distress, few have included positive factors that may increase youth condom use, such as parental support (Fergus \& Zimmerman, 2005). Studies that do not include the assets and resources available to youth when examining their risk-taking behaviors provide only a partial picture of their developmental context and perpetuate a deficit approach to understanding youth development. Using resiliency as a theoretical framework to guide our hypotheses, we emphasize the presence of both risk and promotive factors in the lives of the African-American youth in our study.

Specifically, we argue that the inclusion of promotive factors may diminish the observed relationship between risk factors and negative outcomes. Thus, using this protective model, the current study aims to understand whether parental support in the lives of African-American youth can help promote consistent condom use throughout adolescence and into young adulthood, even in the presence of youth's own substance use and psychological distress, factors known to increase sexual risk (Elkington, Bauermeister, \& Zimmerman, 2010b; Elkington et al., 2008). 


\section{Risk Factors Inhibiting Consistent Condom Use}

Substance use and psychological distress have received substantial attention in studies of adolescent sexual risk behavior. Researchers have found persistent negative associations between substance use and consistent condom use among adolescents (Lowry et al., 1994; Malow, Devieux, Jennings, Lucenko, \& Kalichman, 2001; Morrison, DiClemente, Wingood, \& Collins, 1998; National Center on Addiction \& Substance Abuse at Columbia University, 1999; Poulin \& Graham, 2001; Shrier, Emans, Woods, \& Durant, 1997; Wingood \& DiClemente, 1998) and young adults (Graves \& Leigh, 1995; Testa \& Collins, 1997). The majority of these studies, however, are cross-sectional and do not describe how these associations may change over time, nor do they examine the influence of promotive factors such as parental support in offsetting this risk across adolescence and into young adulthood. Thus, we have a limited and incomplete understanding of the nature of the relationship between substance use and sexual risk behavior during the transition from adolescence to young adulthood in African-American youth.

Researchers have also found that for adolescents, including African-American and other minority youth, psychological distress (i.e., symptoms of depression and anxiety) is negatively associated with consistent condom use (Elkington et al., 2010b; Joffe \& Radius, 1993; Lehrer, Shrier, Gormaker, \& Buka, 2006; Morrison-Beedy, Carey, Feng, \& $\mathrm{Tu}, 2008$; Seth, Raiji, DiClemente, Wingood, \& Rose, 2009; Shrier, Harris, Sternberg, \& Beardslee, 2001; Shrier et al., 1997). Depression and its correlates of low motivation, hopelessness, helplessness, and low self-esteem may make it more difficult for an individual to adopt and maintain safer sexual practices (Brooks-Gunn \& Paikoff, 1997; Brown et al., 2006). Psychological distress has also been found to be associated with lower self-efficacy to negotiate consistent condom use (Salazar et al., 2004) and greater likelihood of reporting an STI (Shrier, Harris, \& Beardslee, 2002). Additional studies among African-American youth in particular have confirmed the relationship between low selfesteem and sexual risk behavior (Belgrave, Van Oss Marin, \& Chambers, 2000; Salazar et al., 2005; Wills et al., 2007). Only one of these studies investigated how psychological distress may be related to African-American adolescents' trajectories of sexual risk behavior (Elkington et al., 2010b). Utilizing the same sample as the present study, Elkington et al. (2010b) found that substance use fully mediated the relationship between psychological distress and condom use, yet risk was only examined in adolescence, omitting the young adulthood years. Thus, building on this previous work, we include an analysis of how trajectories of substance use and psychological distress may be related to sexual risk behavior, specifically condom use, among AfricanAmericans transitioning to adulthood. These data will help us understand how these factors influence sexual risk trajectories. In keeping with a resiliency framework, however, in the present study we seek to examine how positive factors may offset or diminish the influence of these risk factors over time.

\section{Parental Support}

Scholars have proposed that parental support is a key factor in the healthy development of adolescents (Repetti et al., 2002) and young adults (Hair et al., 2008), including healthy sexual development and reduced sexual risk (Donenberg et al., 2006; Meschke, Bartholomae, \& Zentall, 2000; Repetti et al., 2002). Studies of parental support and sexual risk among African-American adolescents, however, have yielded mixed findings. Some researchers have found that parental support reduces sexual risk among adolescents (Crosby et al., 2001; Deptula, Henry, \& Schoeny, 2010; Dittus, Jaccard, \& Gordon, 1997; Jaccard, Dittus, \& Gordon, 1996), others have reported no relationship (Lauritsen, 1994; Perkins, Luster, Villaruel, \& Small, 1998), and still others have suggested that parental support increases sexual risk (Tolou-Shams, Paikoff, McKirnan, \& Holmbeck, 2007). These different findings may be attributable to sample characteristics (e.g., whether or not the individual lives in a household with both parents); the type of parental support measured, be it global (i.e., a broad measure including all types of support) or emotional (i.e., support specifically related to the provision of caring and encouragement); or the analytic technique used to examine the effects of parental support.

Studies of the effects of parental support on youth sexual risk behaviors have focused largely on the adolescent developmental period, whereas similar processes in young adulthood are neglected in the literature. When young adulthood is considered, it has often been treated as a follow-up period where we may understand the prospective effects of parental support in adolescence. In a multiethnic sample, for example, Gillmore, Chen, Hass, Kopak, and Robillard (2011) found that increased family support in adolescence was 
associated with increased condom use in young adulthood. More importantly, these results held for the sample as a whole, but were not significant when African-Americans were considered in a subanalysis. This finding suggests that condom trajectories may be different for African-American youth. We therefore highlight the need for a study which grants equal measure to the potential effects of parental support in the adolescent and young adulthood period, particularly among AfricanAmerican youth.

Few researchers have examined the association between parental support and youth condom use specifically (Deptula et al., 2010; Gillmore et al., 2011). In each of these studies, parental support was associated with consistent condom use; however, most researchers who have examined the relationship between African-American adolescents' sexual risk behaviors and parental support have included only measures of maternal support (Hutchinson, Jemmott, Jemmott, Braverman, \& Fong, 2003; Taris \& Semin, 1997; Weinstein \& Thornton, 1989) or have not distinguished maternal and paternal support (Rodgers, 1999). As a result, the influence of fathers' support on adolescent sexual behavior has received little attention. From a public health standpoint, the absence of such data may be perceived as suggesting that fathers do not play a part in the sexual development of their children. Given the need for family-based HIV intervention programs (Donenberg et al., 2006; Elkington, Bauermeister, \& Zimmerman, 2010a), it is vital to understand if fathers influence their youth's sexual well-being and whether or not they should be included in future sexual health programs.

Researchers have acknowledged that AfricanAmerican fathers may help socialize their adolescent children (McLoyd, Cauce, Takeuchi, \& Wilson, 2000), help protect them from risks for violent behavior (Zimmerman, Steinman, \& Rowe, 1998), or help them avoid problem behaviors (Zimmerman, Salem, \& Notaro, 2000) even if they do not reside in the same household. Finally, little is known about how support received from mothers may differ from support received from fathers in reducing sexual risk behavior in African-American youth. The few researchers that have examined parental influences on youth sexual risk behavior have found that fathers' disapproval of sexual behavior may decrease the sexual risk behaviors of their children, independent of mothers' attitudes (Dittus et al., 1997), and that fathers may even have a stronger effect than mothers on reducing daugh- ters' sexual risk behavior (Peterson, 2007). These studies, however, did not include emotional support, were cross-sectional (or with few waves of data), did not employ resiliency theory to guide the work, and did not examine the unique contributions of father and mother support. Thus, a focus of this study is to investigate how parental support may offset risk posed by youth psychological distress and substance use and also to examine how support received from the mother and father may independently operate to influence condom use during adolescence and the transition to adulthood.

\section{Study Goals and Hypotheses}

The present study contributes to research on HIV or STI risk behavior and resiliency among AfricanAmerican youth in three critical ways. First, we examine the changes in condom use across adolescence and into young adulthood in a sample of urban African-American youth accounting for two significant risk factors for sex risk behavior-psychological distress and substance use-also over time. Consistent with past studies, we hypothesize that condom use will decrease over time for the sample, particularly if youth report greater psychological distress and substance use. Second, we explore whether or not African-American youth's condom use over time is associated with parental support across adolescence and young adulthood. Guided by a resiliency perspective, we hypothesize that both maternal and paternal support will be associated with increased condom use and diminish psychological distress and substance use over time. Finally, we examine whether or not the relationship between condom use and maternal support differs from the relationship observed between condom use and paternal support. We hypothesize no parental differences, underscoring the significant role fathers may play in African-American youth's well-being.

\section{METHOD}

This study is based on a 12-year longitudinal study of youth from mid-adolescence (i.e., high school years) to emerging adulthood. We collected data from 850 adolescents who were at-risk for high school dropout beginning their 9th grade (Wave 1: 1994) in four public high schools in a Midwestern city. All 9th graders from these schools were recruited with the assistance of school personnel, excluding those with a diagnosis of emotional or 
mental disability. Previous studies with the same sample have found adolescents had a more even distribution of grade point average (GPA) by Wave 4 (12th grade) of the study (Zimmerman, Caldwell, \& Bernat, 2002). Waves 1 through 4 correspond to the participants' high school years. Waves 5 through 8 correspond to the second through fifth posthigh school years, regardless of whether or not they graduated from high school.

\section{Sample}

Adolescents self-reporting as African-American constituted $80 \%$ of the sample in Wave $1(n=681)$. The current study includes only the African-American subsample because they are at greater risk for early sexual debut, unintended pregnancies, and STIs or HIV infection when compared to their Latino and White counterparts (CDC, 2006, 2008), and have been understudied in the scientific literature compared to White youth. We focus on Waves 2 through 8 in this analysis because the parental support measure was not asked independently for mothers and fathers in Wave 1 . The mean age at Wave 2 for the remaining 627 African-American participants $(53 \%$ female) was 14.86 years $(S D=0.64)$.

\section{Procedure}

Structured face-to-face interviews were conducted with students by six trained personnel from the
Program in Urban and Regional Affairs (PURA), formerly a research program office at the University of Michigan-Flint. Interviews were conducted in the school or in a community setting if the participants could not be found in school. Waves 5 through 8 interviews were mostly conducted in a community setting. Interviews averaged 50-60 min and covered a myriad of topics, including parental, peer, and spousal support; eating and physical activity habits; future orientation; psychological distress; and prosocial involvement. After the interview portion of the protocol, participants completed a self-administered paper and pencil questionnaire about alcohol and substance use, sexual behavior, and other sensitive information. We defined sex as sexual intercourse. The study had a $90 \%$ response rate over the first four Waves of data collection and a $68 \%$ response rate over all eight Waves.

\section{Measures}

Means and standard deviations for each measure are presented in Tables 1 and 2 .

\section{Time-Varying Covariates}

Consistency of condom use. Participants selfreported how consistent condom use was over the previous year (How often have you used a condom when having sex in the last year?), responding

TABLE 1

Descriptive Statistics for Time-Invariant Covariates

\begin{tabular}{|c|c|c|c|c|}
\hline & & SES $($ Range $=29.28-64.38)$ & Father in Home ( $0-4$ years) & In a Serious Relationship (0-4 years) \\
\hline & $N$ & Mean $(S D)$ & Mean $(S D)$ & Mean $(S D)$ \\
\hline Females & 360 & $39.18(9.02)$ & $0.90(1.58)$ & $1.54(1.31)$ \\
\hline Males & 347 & $40.51(10.45)$ & 1.25 (1.76) & $1.16(1.17)$ \\
\hline
\end{tabular}

TABLE 2

Descriptive Statistics for Time-Varying Covariates Across Adolescence and Young Adulthood

\begin{tabular}{|c|c|c|c|c|c|c|c|}
\hline & Age & Condom Use & Number of Partners & $\begin{array}{l}\text { Substance Use } \\
\text { (z score) }\end{array}$ & $\begin{array}{c}\text { Psychological Distress } \\
\text { (z score) }\end{array}$ & Mother Support & Father Support \\
\hline Wave & Mean (SD) & Mean (SD) & Mean (SD) & Mean (SD) & Mean (SD) & Mean (SD) & Mean (SD) \\
\hline 2 & $15.89(0.64)$ & $3.45(1.07)$ & $2.04(2.84)$ & $1.43(2.37)$ & $0.80(0.81)$ & $3.01(0.96)$ & $2.10(1.36)$ \\
\hline 3 & $16.85(0.65)$ & $3.32(1.14)$ & $2.20(3.13)$ & $1.44(2.47)$ & $0.75(0.77)$ & $3.10(0.95)$ & $2.32(1.29)$ \\
\hline 4 & $17.83(0.65)$ & $3.08(1.27)$ & $1.88(2.28)$ & $1.54(2.59)$ & $0.77(0.89)$ & $3.03(0.99)$ & $2.19(1.32)$ \\
\hline 5 & $20.06(0.66)$ & $2.33(1.50)$ & $2.77(3.35)$ & $1.85(2.74)$ & $0.66(0.62)$ & $3.03(1.02)$ & $2.14(1.22)$ \\
\hline 6 & $20.99(0.64)$ & $2.62(1.57)$ & $1.77(1.97)$ & $1.98(2.79)$ & $0.63(0.62)$ & $3.00(1.01)$ & $2.19(1.26)$ \\
\hline 7 & $22.07(0.67)$ & $2.50(1.58)$ & $1.80(2.02)$ & $2.27(2.90)$ & $0.70(0.62)$ & $2.96(1.02)$ & $2.25(1.24)$ \\
\hline 8 & $23.06(0.68)$ & $2.58(1.63)$ & $2.56(8.55)$ & $2.27(3.00)$ & $0.66(0.61)$ & $2.99(1.05)$ & $2.30(1.22)$ \\
\hline
\end{tabular}


with one of the following categories: $0=$ Almost never, $1=$ Not very often, 2 = Half of the time, $3=$ Most of the time, and $4=$ Always. Participants who reported never having had sexual intercourse or not having had sex in the previous year were coded as 4 (i.e., always) for that particular wave because we were adjusting for number of lifetime sexual partners.

Number of partners. Participants reported the number of sexual partners in their lifetime using an open-ended question format at Wave 1 ("How many partners have you had?"). For all other waves, participants self-reported the number of sex partners in the past year by answering an openended question ("How many sex partners have you had in the last year?"). Participants were assigned a value of zero if they had not been sexually active in a given wave.

Substance use. Alcohol and marijuana use were measured with the same questions employed by the Monitoring the Future Study (Staff et al., 2010). Questions included frequency of alcohol and marijuana use, respectively, over the past year on a 7point Likert scale ( $0=0$ times; $6=40+$ times $)$. We created a standardized substance use composite score for each wave based on the mean standardized value of participants' frequency of alcohol and marijuana use.

Psychological distress. Two indicators of psychological distress, depression (six items) and anxiety (six items), were measured using the Brief Symptom Inventory (Derogatis \& Spencer, 1982). Participants answered these items using a 5-point scale ranging from $1=$ Never to $5=$ Very Often. We created a standardized psychological wellbeing composite score for each Wave based on participants' mean standardized values for depression and anxiety symptoms, respectively. Across the 8 years, the reliability for the depression scale ranged between 0.79 and 0.84 and between 0.77 and 0.89 for anxiety.

Mother and father support. Parental support was an abbreviated version of Procidano and Heller's (1983) scale. The scale includes five items: (1) "My parents enjoy hearing about what I think,"

(2) "I rely on my parents for emotional support," (3) "My parents are good at helping me solve problems," (4) "I have a deep sharing relationship with my parents," and (5) "My parents encourage me to stay in school." For each of these five items, partici- pants indicated their level of agreement on a scale from 1 (Not True) to 5 (Very True). We reworded these items to assess parental support offered by male and female caregivers, respectively. At each wave, youths were asked to answer these five items for their mother or the woman they consider their mother. Similarly, youths were asked to answers these five items for their fathers or the man they consider their father. Higher mean scores in mother and father support scores, respectively, indicate higher emotional support. Youth answered the support questions whether or not they lived with a parent. Reliability coefficients over time ranged between 0.88 and 0.94 for mother support and between 0.93 and 0.95 for father support.

\section{Time-Invariant Covariates}

Sociodemographic characteristics. We included several demographic factors that have been found to be related to various factors in our theoretical model including youth's gender (Caldwell, Sellers, Bernat, \& Zimmerman, 2004; Colarossi, 2001; Newman \& Zimmerman, 2000; Wills, Gibbons, Gerrard, Murry, \& Brody, 2003) and socioeconomic status (Cleveland, Gibbons, Gerrard, Pomery, \& Brody, 2005; Kim \& Brody, 2005; Wills et al., 2003). These demographic characteristics were collected from participants at Wave 1. Participants were asked to report their date of birth and gender. Age was computed by subtracting each interview's date to participants' month and year of birth.

We used two measures of socioeconomic status. First, we included maternal education. Participants reported their mother's highest level of education $(1=$ Completed grade school or less; $3=$ Completed high school; $5=$ Some college; $7=$ Graduate school). On average, youth reported their mothers had at least a high school education $(M=4.04$, $S D=1.36$ ). Second, we include an occupational prestige score based on their parents' occupations. Occupations were assigned a prestige score using Nakao and Treas' classification and rating scheme (Nakao \& Treas, 1994). The lowest group received a score of 29.28 (private household workers) and the highest occupational group received a score of 64.38 (professional). If scores were available for both parents, the higher prestige score was used for analysis. Parents of youth were mostly blue-collar workers from the local factories. The mean prestige score was $39.86(S D=9.78)$.

Furthermore, we accounted for two spurious factors that may influence the change of condom use over time. The first factor, father in home, may 
influence the relationship between father support and condom use. During the adolescent years (Waves 1 through 4), we asked participants to report if their father lived in the home $(0=$ No, $1=$ Yes $)$. We used this item to create a sum score reflecting the number of years that youths reported living with their fathers. The mean number of years was 1.12 $(S D=1.71)$. We did not use a similar measure for mothers, as a previous study with this sample reported that $86 \%$ of participants were living with their mothers (Salem, Zimmerman, \& Notaro, 1998). Second, we examined whether or not youth were in a serious relationship during the transition to adulthood years (i.e., approximately ages 20-23; Thorburn, Harvey, \& Ryan, 2005). We computed the number of years during young adulthood that participants reported being in a serious relationship $(0=$ No, $1=$ Yes $)$ as it may influence their condom decisions. The mean number of years in a serious relationship was $1.37(S D=1.26)$.

\section{Data Analytic Strategy}

We used HLM 6.08 (SSI, 2005) for our growth curve model analyses. While a repeated measures regression performs list-wise deletion for cases with missing values in one or more data points, HLM maximizes all available data by employing an Expectation-Maximization (EM) algorithm if participants do not have information across all waves when computing growth curve estimates (Raudenbush \& Bryk, 2002). Similar to repeated measures regression, multilevel modeling allows the total variance to be divided into within-individual (Level One Model; i.e., change over time) and between-individual (Level Two Model; i.e., personcentered characteristics like gender) variation.

We modeled youth condom use over time using an age-centered approach (i.e., change in condom use for every year increase across adolescence and young adulthood). Since this study covers the adolescent and the early adulthood periods, we model different growth rates that may exist for each developmental period (see Bauermeister, Zimmerman, Gee, Caldwell, \& Xue, 2009). Piecewise growth curve models offer improved substantive and analytically appropriate model specifications for longitudinal studies across different developmental periods (Chou, Yang, \& Hser, 2004). Therefore, we parceled the growth parameters into adolescent $\left(\pi_{1}\right.$, ages $\left.15-18\right)$ and early adulthood $\left(\pi_{2}\right.$, ages 19-24) piecewise estimates (see Appendix for piecewise coding). We also included a quadratic term of a linear piecewise growth parameter when the slope had a curvilinear trend $\left(\pi_{3}\right)$. The linear time coefficient estimated the constant change in condom use over time, and the nonlinear growth estimates approximated its mean acceleration or deceleration over time. If the intercept (i.e., Mean condom use at age $15 ; \pi_{0}$ ) or any growth term varied between individuals, we explored whether or not person-centered characteristics (e.g., gender, SES, participating in serious relationship) explained condom use over time (Model 1):

$$
\begin{aligned}
\text { Condom Use } & =\pi 0 i+\pi 1 i(\text { Adol.Age })+\pi 2 i(\text { YAAge }) \\
& +\pi 3 i(\text { YAAge })+e_{t i} \pi 0 i \\
& =\beta_{00}+\beta_{01}(\text { Female })+\beta_{02}(\text { Relationship })+r_{0 i} \\
\pi 1 i & =\beta_{10}=\beta_{11}(\text { Female })+r_{1 i} \\
\pi 2 i & =\beta_{20}=\beta_{21}(\text { Female })+\beta_{22}(\text { Relationship })+r_{2 i} \\
\pi 3 i & \left.=\beta_{30}=\beta_{31}(\text { Female })+\beta_{32} \text { (Relationship }\right)+r_{3 i}
\end{aligned}
$$

Once the change in condom use time was modeled, we included youth's number of partners, substance use, and psychological distress as timevarying control variables (Model 2). We found no between-individual differences in these time-varying covariates; consequently, we only present changes to the Level One model.

$$
\begin{aligned}
\text { Condom Use } & =\pi 0 i+\pi 1 i(\text { Adol. Age })+\pi 2 i(\text { YA Age }) \\
& +\pi 3 i\left(\text { YA Age } e^{2}\right)+\pi 4 i(\text { Partners }) \\
& +\pi 5 i(\text { Psych Distress }) \\
& +\pi 6 i(\text { Substance Use })+e_{t i}
\end{aligned}
$$

Finally, we entered maternal and parental support into our growth curve model (Model 3):

$$
\begin{aligned}
\text { Condom Use } & =\pi 0 i+\pi 1 i(\text { Adol. Age })+\pi 2 i(\text { YA Age }) \\
& +\pi 3 i(\text { YA Age })+\pi 4 i(\text { Partners }) \\
& +\pi 5 i(\text { Psych Distress })+\pi 6 i(\text { Substance Use }) \\
& +\pi 7 i(\text { Mother Support }) \\
& +\pi 8 i \text { (Mother Support })+e_{t i}
\end{aligned}
$$

In sensitivity analyses, we parceled the two parental support time-varying covariates into four piecewise estimates (i.e., maternal and parental support in adolescence, and maternal and parental support in young adulthood, respectively) and reran Model 3; however, this model is not presented as it had a poor fit due to multicollinearity issues between each parent's adolescent and young adulthood support slopes, respectively (data not shown).

We present these stepwise analyses in Table 3. Given the number of variables in these analyses, we present a final growth curve model excluding 
those predictors found to be nonsignificant $(p \leq .05)$. We examined and tested the overall improvement in model fit at each step using the log likelihood coefficient (-2LL).

\section{RESULTS}

\section{Model 1: Condom Use Over Time}

On average, condom use at age 15 was high $(B=3.84 ; p<.001)$; however, female participants reported less condom use than male participants $(B=0.29 ; \quad p<.01)$. Furthermore, youth who reported a greater number of years in a serious relationship during young adulthood were less likely to report using condoms at age 15 $(B=-0.09 ; p<.01)$. Household SES was not associated with mean condom use at age 15 .

The growth of condom use over time was best modeled by including a linear term for the adolescent years and a linear and quadratic term for the young adulthood years (see Figure 1). We found random variation in these piecewise growth slopes. Consequently, we examined whether or not condom use over time varied differently across person-centered characteristics.

As shown in Figure 1, condom use decreased across adolescence $(B=-0.19 ; p<.001)$, but female participants had a steeper decrease than male participants $(B=-0.09 ; p<.05)$. No other person-centered characteristic moderated the change in condom use across adolescence. During the young adulthood years, we found that youth's condom use $(B=0.36, p<.001$ for linear term; $B=-0.07$, $p<.01$ for quadratic term) decreased with each year that youth had participated in one or more serious relationships across the young adulthood years $(B=-0.22, p<.001$ for linear term; $B=0.04$, $p<.01$ for quadratic term). We found no other person-centered characteristics in youth's condom use during young adulthood.

\section{Stepwise Inclusion of the Time-Varying Covariates}

Model 2: Substance use, psychological distress, and number of partners. When we included the three time-varying covariates in our growth model, we found a significant improvement in model fit (see Table 3). We found youth condom use decreased over time if youth had reported greater psychological distress $(B=-0.08, p<.05)$ and substance use $(B=-0.04, p<.001)$. We found no association between condom use and number of partners over time. We treated these time-varying covariates as fixed effects given that they were treated as control variables in our analyses.

Model 3: Mother and father support. We found a significant improvement in our model's fit when we included the parental support coefficients in the analysis (see Table 3). Furthermore, when the support covariates were included in the analyses, the relationship between condom use and psychological distress disappeared. The relationship between substance use and condom use remained, however, even in the presence of mother and father support. More condom use was associated with mother $(B=0.12, p<.001)$ and father $(B=0.07, p<.01)$ support over time (see Figure 2 ). We found no differences across person-centered characteristics in the relationship between condom use and mother support or father support, respectively. Furthermore, we carried out a $t$-test to compare whether or not the magnitude of the slope for mother support was statistically greater than the slope for father support (i.e., Ho: $B_{70}-B_{80}=0$ ). We found no evidence to suggest that the relationship between condom use and mother support over time was greater than the relationship between condom use and father support over time.

We also performed the necessary post hoc tests for mean differences, in each wave, for each of our covariates (age, number of partners, substance use, psychological distress, mother support, and father support), between youth who reported never having used condoms and those who had. After applying a Bonferroni correction, we found mean differences for number of partners in three of the four young adult waves. Youth who reported never using condoms reported significantly fewer partners. We attribute this finding to youths' engagement in serious relationships, and, having accounted for serious relationship status in our longitudinal multivariate analyses, it was not surprising that number of partners was nonsignificant.

\section{DISCUSSION}

During the transition from adolescence to young adulthood, youth engage in decision-making that will likely influence their behavioral trajectories well into adulthood (Arnett, 2000). Much of the prior research examining sexual risk behavior in adolescence and young adulthood has neglected to examine these two developmental periods together, particularly in studies of African-American youth. Utilizing seven waves of data, we found different 
TABLE 3

Hierarchical Growth Curve Model of Consistent Condom Use Over Adolescence and Young Adulthood

\begin{tabular}{|c|c|c|c|}
\hline & $B$ & $S E$ & $p$-value \\
\hline \multicolumn{4}{|l|}{ Model 1: Base model } \\
\hline $\begin{array}{l}\text { Mean initial condom use score } \\
\text { (age 15), } B_{00}\end{array}$ & 3.84 & 0.07 & $* * *$ \\
\hline Female, $B_{01}$ & -0.29 & 0.09 & ** \\
\hline $\begin{array}{l}\text { Number of years in serious } \\
\text { relationship, } B_{02}\end{array}$ & -0.09 & 0.03 & ** \\
\hline $\begin{array}{l}\text { Mean linear change in } \\
\text { adolescence, } B_{10}\end{array}$ & -0.19 & 0.03 & $* * *$ \\
\hline Female, $B_{11}$ & -0.09 & 0.04 & * \\
\hline $\begin{array}{l}\text { Mean linear change in young } \\
\text { adulthood, } B_{20}\end{array}$ & 0.36 & 0.11 & ** \\
\hline Female, $B_{21}$ & 0.14 & 0.15 & \\
\hline $\begin{array}{l}\text { Number of years in serious } \\
\text { relationship, } B_{22}\end{array}$ & -0.22 & 0.04 & $* * *$ \\
\hline $\begin{array}{l}\text { Mean linear change in young } \\
\text { adulthood, } B_{30}\end{array}$ & -0.07 & 0.03 & * \\
\hline Female, $B_{31}$ & 0.01 & 0.04 & \\
\hline $\begin{array}{l}\text { Number of years in serious } \\
\text { relationship, } B_{32}\end{array}$ & 0.04 & 0.01 & ${ }^{* *}$ \\
\hline Deviance (-2LL) & 11778.98 & & \\
\hline \multicolumn{4}{|l|}{ Model 2: Risk model } \\
\hline $\begin{array}{l}\text { Mean initial condom use score } \\
\text { (age 15), } B_{00}\end{array}$ & 3.93 & 0.07 & $* * *$ \\
\hline Female, $B_{01}$ & -0.26 & 0.09 & ** \\
\hline $\begin{array}{l}\text { Number of years in serious } \\
\text { relationship, } B_{02}\end{array}$ & 0.09 & 0.03 & $* * *$ \\
\hline $\begin{array}{l}\text { Mean linear change in } \\
\text { adolescence, } B_{10}\end{array}$ & -0.18 & 0.03 & ${ }^{* * *}$ \\
\hline Female, $B_{11}$ & -0.09 & 0.04 & * \\
\hline $\begin{array}{l}\text { Mean linear change in young } \\
\text { adulthood, } B_{20}\end{array}$ & 0.39 & 0.12 & *** \\
\hline Female, $B_{21}$ & 0.15 & 0.15 & \\
\hline $\begin{array}{l}\text { Number of years in serious } \\
\text { relationship, } B_{22}\end{array}$ & -0.23 & 0.04 & *** \\
\hline $\begin{array}{l}\text { Mean linear change in young } \\
\text { adulthood, } B_{30}\end{array}$ & -0.07 & 0.03 & ** \\
\hline Female, $B_{31}$ & -0.02 & 0.03 & \\
\hline $\begin{array}{l}\text { Number of years in serious } \\
\text { relationship, } B_{32}\end{array}$ & 0.04 & 0.01 & $* * *$ \\
\hline Number of partners, $B_{40}$ & 0.01 & 0.004 & \\
\hline Psychological distress, $B_{50}$ & -0.08 & 0.03 & * \\
\hline Substance use, $B_{60}$ & -0.04 & 0.01 & *** \\
\hline Deviance (-2LL) & 11543.83 & & \\
\hline Model change & 235.15 & & *** \\
\hline DF change & 3 & & \\
\hline \multicolumn{4}{|l|}{ Model 3: Risk and protective model } \\
\hline $\begin{array}{l}\text { Mean initial condom use score } \\
\text { (age 15), } B_{00}\end{array}$ & 3.33 & 0.13 & $* * *$ \\
\hline Female, $B_{01}$ & -0.22 & 0.1 & * \\
\hline $\begin{array}{l}\text { Number of years in serious } \\
\text { relationship, } B_{02}\end{array}$ & -0.09 & 0.03 & $* * *$ \\
\hline $\begin{array}{l}\text { Mean linear change in } \\
\text { adolescence, } B_{10}\end{array}$ & -0.16 & 0.03 & *** \\
\hline Female, $B_{11}$ & -0.10 & 0.05 & 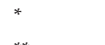 \\
\hline $\begin{array}{l}\text { Mean linear change in young } \\
\text { adulthood, } B_{20}\end{array}$ & 0.40 & 0.14 & ** \\
\hline
\end{tabular}

TABLE 3 (Contd.)

\begin{tabular}{lccc}
\hline & $B$ & $S E$ & $p$-value \\
\hline Female, $B_{21}$ & 0.17 & 0.18 & \\
$\quad$ Number of years in serious & -0.26 & 0.05 & $* *$ \\
$\quad$ relationship, $B_{22}$ & & & \\
Mean linear change in young & -0.08 & 0.04 & $*$ \\
adulthood, $B_{30}$ & & & \\
$\quad$ Female, $B_{31}$ & -0.20 & 0.04 & \\
$\quad$ Number of years in serious & 0.05 & 0.01 & $*$ \\
$\quad$ relationship, $B_{32}$ & & & \\
Number of partners, $B_{40}$ & 0.001 & 0.01 & \\
Psychological distress, $B_{50}$ & -0.05 & 0.04 & $*$ \\
Substance use, $B_{60}$ & -0.03 & 0.01 & $*$ \\
Mother support, $B_{70}$ & 0.12 & 0.03 & $* *$ \\
Father support, $B_{80}$ & 0.07 & 0.02 & \\
Deviance (-2LL) & 8989.46 & & \multirow{*}{*}{ * } \\
Model change & 2854.37 & & \\
DF change & 2 & & \\
\end{tabular}

$$
{ }^{*} p<.05 ;{ }^{* *} p<.01 ;{ }^{* * *} p<.001 .
$$

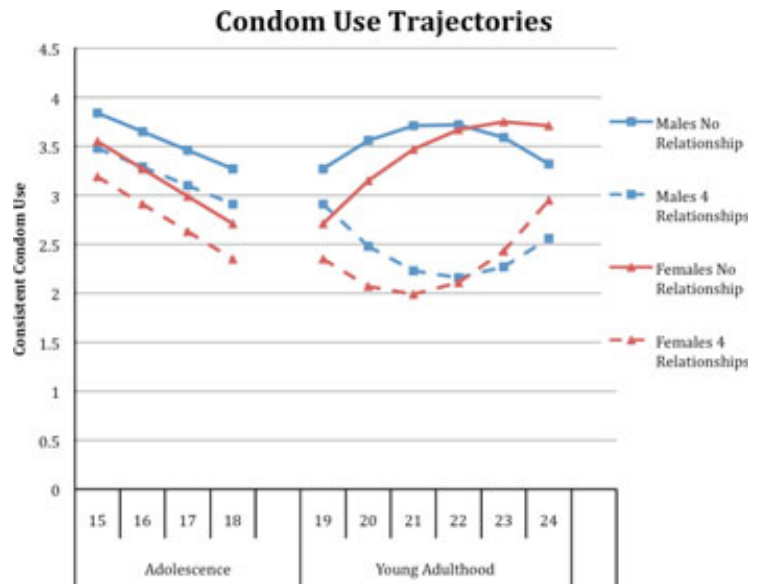

FIGURE 1 Consistent condom use by gender and number of relationships across adolescence and young adulthood.

condom use trajectories for adolescence and young adulthood. The emphasis on these various trajectories is particularly salient because consistent condom use is one of the most effective barriers in preventing the sexual transmission of HIV or STIs and unintended pregnancies. In addition, consistent condom use diminishes the HIV risk posed by other well-known risk factors, such as multiple partners and frequency of sexual intercourse. Overall, African-American youth in our sample decreased their condom use behavior over time. Female youth, in particular, were less likely to report consistent condom use over time. We also found that condom use decreased with every additional year that youth had reported being in a serious relationship during young adulthood. This may reflect finding a partner, gaining an education, 


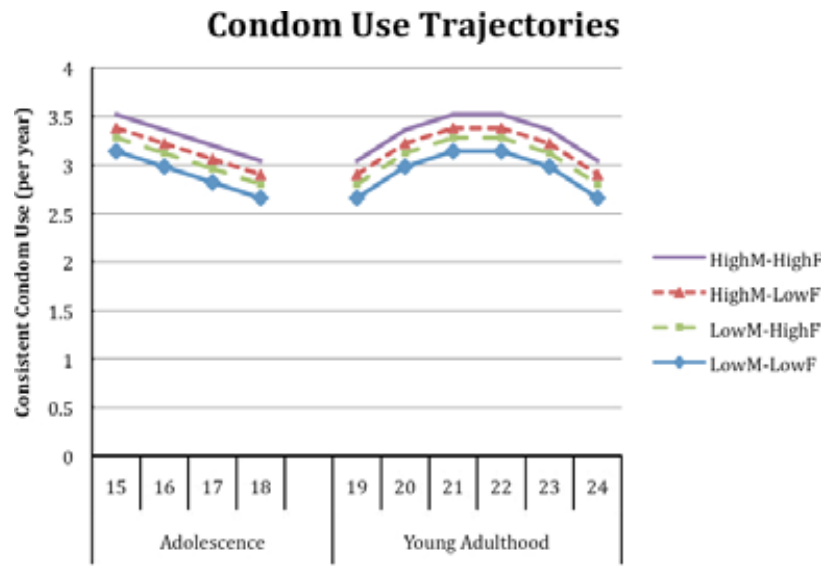

FIGURE 2 Consistent condom use by maternal and paternal social support across adolescence and young adulthood.

starting a family, or beginning a career (Arnett, 2000, 2001). The presence of differential trajectories of condom use in adolescence and young adulthood suggests that interventions for promoting condom use to reduce HIV or STI risk may benefit from tailoring messages and content to the appropriate developmental period.

\section{Risk Factors Inhibiting Consistent Condom Use}

Youth engaging in substance use behavior, and those reporting greater psychological distress, also reported less condom use over all seven waves of our analysis. These findings are consistent with prior research (Houck et al., 2006), but are especially significant given that past research among AfricanAmerican youth is inconsistent with regard to the relationship between consistent condom use and substance use, and virtually nonexistent concerning psychological distress and condom use in young adulthood. Furthermore, few researchers have examined the variation in these risk factors longitudinally, much less in the transition to adulthood. Our results confirm a negative association across time between condom use and substance use and psychological distress, respectively, among AfricanAmerican youth. Consequently, HIV prevention interventions for African-American youth should address substance use and psychological distress as potential risk factors which may inhibit consistent condom use. Nevertheless, as we argue below, these risk factors may be offset by maternal and paternal support.

\section{The Protective Effect of Parental Support}

Consistent with a protective model of resiliency, mother and father support may be characterized as protective factors, in that they directly reduce the effects of known risk factors. In accordance with prior research (Boyer, Tschann, \& Shafer, 1999; St. Lawrence, Brasfield, Jefferson, Alleyene, \& Shirley, 1994), we found that father and mother support were associated with more consistent condom use. Although most researchers examining the relationship between parental support and sexual risk behaviors have focused on maternal support (Hutchinson et al., 2003; Taris \& Semin, 1997; Weinstein \& Thornton, 1989) or grouped maternal and paternal support together (Hadley et al., 2009; Rodgers, 1999), our study indicates that mothers and fathers each provide unique and positive influences on African-American youth's sexual behavior. This finding is consistent with emerging research suggesting that fathers matter just as much as mothers in efforts to reduce sexual risk among their children (Caldwell, Rafferty, Reischl, DeLoney, \& Brooks, 2010; Dilorio, McCarty, \& Denzmore, 2006). Although researchers have noted differences in the relationship between parents' sexual communication for male and female youth (Guilamo-Ramos et al., 2007), we did not find gender differences in the relationship between condom use and paternal or maternal support. One reason for this discrepancy may be that our measure of parental support focused on emotional components, whereas Guilamo-Ramos et al.'s study focused on informational support (e.g., sharing sexual information with their children). These findings suggest that the relationship between youth sexual behavior and parental support may be dependent on the type of social support provided. Future research comparing the association between youth sexual behavior and different parental support types may be warranted and could inform multiple HIV intervention approaches.

Interestingly, the influence of fathers on youths' condom use was not dependent on whether or not the father and youth live in the same household during adolescence. Even though high rates of single-mother headed families among African-Americans have been documented (McLoyd et al., 2000; Murry, Bynum, Brody, Willert, \& Stephens, 2001), these results underscore the importance of father involvement among African-American youth, even when African-American fathers do not live with their children (Caldwell, Bell, Brooks, Ward, \& Jennings, 2011; Dilorio et al., 2006; Salem et al., 1998; Zimmerman, Salem, \& Maton, 1995). Furthermore, this finding supports past research suggesting that family structure does not influence adolescents' sexual risk behavior (Miller, Forehand, \& Kotchick, 
1999). Intervention research focusing on improving father-son dynamics during late childhood (812 years old; Caldwell et al., 2010) and early adolescence (11-14 years old; DiIorio et al., 2006) suggests promising findings for HIV prevention. Consequently, research examining the role of fathers, within or outside the home, in the sexual decision-making processes of African-American adolescents and young adults is warranted, as it may inform HIV or STI prevention efforts (Peterson, 2007; Tolou-Shams et al., 2007).

Mother and father support diminished the negative effects of psychological distress over time on condom use over time. One possible interpretation for this finding is that psychological distress may not be associated with condom use over time if youth have sufficient parental support in their lives, as past findings indicate that lack of parental support may increase youth psychological distress (Auerbach, Bigda-Peyton, Eberhart, Webb, \& Ho, 2010; Barrera \& Li, 1996; McLoyd, 1990). Parental support may therefore be considered a vital resource for reducing the effects of risks even as youth transition into adult roles. On the other hand, we found no evidence to suggest that increased parental support diminished the association between substance use and condom use over time. One plausible explanation for this finding is that youth engage in alcohol and marijuana use with peers, often outside the home. As a phenomenon regulated by peers, youth substance use may occur regardless of the amount of support provided by parents and may instead be better understood in the context of peer influences and risk (Elkington et al., 2010a). In keeping with a resiliency perspective, we believe that both qualitative and quantitative research examining when and how parental and peer support are protective factors over time is warranted. Having established the role of parental support as a likely protective factor against increased sexual risk behavior, it is now necessary to explore further the actual processes by which these support systems exert their influence. Consistent with Elkington et al.'s (2010b) investigation of substance use as a mediator between psychological distress and sexual risk behavior in this same sample, future research should examine more fully the role of substance use, psychological distress, and parental support as potential mediating and moderating factors. By exploring the specific pathways of risk, as well as how these factors may synergize to create greater risk or balance each other out to diminish risk, we can begin to better understand youth's sexual risk trajectories. Finally, from a practice standpoint, our findings support the notion that involving parents in sexual health interventions for youth may be essential to increasing their effectiveness (Donenberg et al., 2006), especially for African-American youth. Specifically, our findings suggest that affective components may be warranted.

\section{Limitations}

Several potential limitations of the study should be considered when interpreting the findings. One category of limitations has to do with the study's sample. Only those students with 8th-grade GPAs of 3.0 or lower were included in the data set, so the results may not be generalizable to adolescents more generally because the sample may have excluded adolescents less likely to engage in sexual risk behavior (Halpern, Joyner, Udry, \& Suchindran, 2000). By 12th grade, however, the sample's average GPA resembled a more normal distribution (Zimmerman et al., 2002), somewhat mitigating this concern. Since the sample is drawn from a medium-sized city, it may also not be generalizable to adolescents who live in other environments, such as in large cities or rural areas. Nevertheless, African-Americans living in smaller cities have often been neglected in studies of minority youth which tend to focus on samples from large cities. Moreover, longitudinal studies of African-American youth that also include the transition to young adulthood are limited.

Our study also does not include measures of specific processes that may explain our findings. Our general measure of parental support, for example, makes it difficult to ascertain how emotional support may influence sexual risk behaviors of youth, or how this support becomes translated into behavior. Furthermore, different components of support-emotional, instrumental, informational, and appraisal (Heaney \& Israel, 2002) - may not be equally salient for youth and may differ in predicting sexual risk behavior during the adolescent and adult transitional periods. It may also be that higher levels of support from parents are associated with some third variable such as parental monitoring, which has an even greater effect on sex risk behavior (DiClemente et al., 2001; Rai et al., 2003). Alternatively, youth who perceive more support from their parents may be more likely to disclose emotional events and to use healthy coping mechanisms for dealing with difficult emotions instead of engaging in risky sexual activity (Brooks-Gunn \& Paikoff, 1997). Finally, 
more general parental support may be associated with parent-child communication concerning sexuality, which may discourage sexual risk behavior (Whitaker \& Miller, 2000). Thus, although this study represents initial evidence that parents can influence their children's sexual risk behavior during adolescence and the transition to adulthood, future research directed toward identifying the specific processes through which the relationship between father and mother support and sexual risk behavior may operate, particularly among AfricanAmericans, would be beneficial.

Another limitation of the study is that we did not control for relationship status during adolescence because this measure was not collected in the first 4 years. Consequently, we acknowledge that adolescents who were involved in serious, monogamous relationships during high school are grouped with those engaged in multiple partnerships over the same time period. Although those in monogamous relationships may have decreased their risk of HIV or STI infection, they may have nevertheless increased their risks for unintended pregnancies, thus still engaging in risky sexual behavior. Controlling for relationship status in adolescence, however, may not be as vital as controlling for relationship status in the transition to adulthood, because adolescents tend to have shorter-term relationships (Rosenthal, Lewis, \& Cohen, 1996; Taradash, Connolly, Pepler, Craig, \& Costa, 2001), and are more likely to report being serially monogamous (Norris \& Ford, 1999). Finally, youth may have changing interpretations of sex (e.g., touching vs. penetration), which may have increased our measurement error. In addition, both consistent condom use and substance use were collected via self-report. We acknowledge the possibility that these data were under-reported in this sample (Henrich, Brookymeyer, Shrier, \& Shahar, 2006; Tourangeau, Rips, \& Rabinski, 2000), yet despite the potential for under-reporting (and therefore less variation to detect relationships), we nevertheless were able to uncover meaningful relationships among the variables of interest (i.e., these relationships would be stronger if data were not under-reported).

\section{CONCLUSION}

Despite these limitations, the results of the study add new information about the role of parents in adolescent and young adult sexual risk behavior. The results suggest that future longitudinal research on the role of mother and father support is warranted, particularly as youth enter young adulthood. Based on our findings, we also recommend the implementation of sexual risk reduction interventions that take into account both the potential mental health needs and substance use issues of the population of focus. Without due attention to these two areas, individuals may find themselves lacking the necessary tools to negotiate condom use in a variety of risk contexts.

The results also further our understanding of the influence of parents as youth age, suggesting that parents are important in offsetting risk for HIV or STI and unintended pregnancy not only in adolescence but into young adulthood. A substantial body of literature has identified numerous aspects of parental or family influence that are critical to HIV risk behaviors in adolescents (Crosby et al., 2001; Deptula et al., 2010; Dittus et al., 1997; Gillmore et al., 2011; Jaccard et al., 1996). It is likely that parent-adolescent communication about sensitive topics, such as sex, is more effective in reducing risk in the context of a positive and supportive parent-child relationship. Thus, the family context is now emerging as a key focal point for sexual risk interventions in youth (Donenberg et al., 2006; Perrino et al., 2000). However, many existing efficacious parent- or familybased interventions targeting parent-youth relationships involve younger youth $(\leq 14$ years $)$ or those who may not be sexually active (DiIorio et al., 2006; Forehand et al., 2007; McKay et al., 2004). Findings from the current study suggest that HIV or STI interventions that target parental support and are developed for older youth are also necessary. In particular, policies designed to involve African-American mothers and fathers in their children's lives, including nonresident fathers (Caldwell, Zimmerman, \& Isichei, 2001; Caldwell, Wright et al., 2004), may be successful at reducing sexual risk behaviors, rates of HIV and other STDs, and unintended pregnancies among African-American youth as they age. Such policies ought to give equal weight to mother and fathers, consistent with our findings and those of others (Caldwell et al., 2010), that fathers have as much of a role to play as mothers in shaping healthy behaviors among youth. 


\section{APPENDIX}

\begin{tabular}{|c|c|c|c|c|c|c|c|c|c|c|}
\hline \multirow{2}{*}{$\begin{array}{c}\text { Piecewise coding } \\
\text { scheme }\end{array}$} & \multicolumn{10}{|c|}{ Age } \\
\hline & 15 & 16 & 17 & 18 & 19 & 20 & 21 & 22 & 23 & 24 \\
\hline $\begin{array}{l}\text { Adolescence linear } \\
\text { piecewise }\end{array}$ & 0 & 1 & 2 & 3 & 3 & 3 & 3 & 3 & 3 & 3 \\
\hline $\begin{array}{l}\text { Adolescence } \\
\text { quadratic } \\
\text { piecewise }\end{array}$ & 0 & 1 & 4 & 9 & 9 & 9 & 9 & 9 & 9 & 9 \\
\hline $\begin{array}{l}\text { Early adulthood } \\
\text { linear piecewise }\end{array}$ & 0 & 0 & 0 & 0 & 1 & 2 & 3 & 4 & 5 & 6 \\
\hline $\begin{array}{l}\text { Early adulthood } \\
\text { quadratic } \\
\text { piecewise }\end{array}$ & 0 & 0 & 0 & 0 & 1 & 4 & 9 & 16 & 25 & 36 \\
\hline
\end{tabular}

\section{REFERENCES}

Arnett, J. J. (2000). Emerging adulthood: A theory of development from the late teens through the twenties. American Psychologist, 55, 469-480.

Arnett, J. J. (2001). Conceptions of the transition to adulthood: Perspectives from adolescence through midlife. Journal of Adult Development, 8, 133-143.

Auerbach, R. P., Bigda-Peyton, J. S., Eberhart, N. K., Webb, C. A., \& Ho, M. H. (2010). Conceptualizing the prospective relationship between social support, stress, and depressive symptoms among adolescents. Journal of Abnormal Child Psychology, 39, 478-487.

Barrera, M., \& Li, S. A. (1996). The relation of family support to adolescents' psychological distress and behavior problems. In G. R. Pierce, B. R. Sarason, \& I. G. Sarason (Eds.), Handbook of social support and the family (pp. 313-344). New York, NY: Plenum Press.

Bauermeister, J. A., Zimmerman, M. A., Gee, G. C., Caldwell, C., \& Xue, Y. (2009). Work and sexual trajectories among African American youth. Journal of Sex Research, 46, 290-300.

Belgrave, F., Van Oss Marin, B., \& Chambers, D. B. (2000). Cultural, contextual, and intrapersonal predictors of risky sexual attitudes among urban African American girls in early adolescence. Cultural Diversity $\mathcal{E}$ Ethnic Minority Psychology, 6, 309-322.

Bingham, C. R., \& Crockett, L. J. (1996). Longitudinal adjustment patterns of boys and girls experiencing early, middle, and late sexual intercourse. Developmental Psychology, 32, 647-658.

Boyer, C. B., Tschann, J. M., \& Shafer, M. A. (1999). Predictors of risk for sexually transmitted diseases in ninth grade urban high school students. Journal of Adolescent Research, 14, 448-465.

Brooks-Gunn, J., \& Paikoff, R. (1997). Sexuality and developmental transitions during adolescence. In J. Schulenberg, J. L. Maggs, \& K. Hurrelmann (Eds.), Health risks and developmental transitions during adolescence (pp. 190219). New York, NY: Cambridge University Press.
Brown, L. K., Tolou-Shams, M., Lescano, C., Houck, C., Zeidman, J., Pugatch, D., \& Lourie, K. J. (2006). Depressive symptoms as a predictor of sexual risk among African American adolescents and young adults. Journal of Adolescent Health, 39, 444.e1-444.e8.

Browning, C. R., Leventhal, T., \& Brooks-Gunn, J. (2005). Sexual initiation in early adolescence: The nexus of parental and community control. American Sociological Review, 70, 758-778.

Caldwell, C. H., Bell, L., Brooks, C. L., Ward, J. D., \& Jennings, C. (2011). Engaging nonresident African American fathers in intervention research: What practitioners should know about parental monitoring in nonresident families. Research on Social Work, 3, 298-307.

Caldwell, C. H., Rafferty, J., Reischl, T., DeLoney, E., \& Brooks, C. L. (2010). Enhancing parenting skills among nonresident African American fathers as a strategy for preventing youth risky behaviors. American Journal of Community Psychology, 45, 17-35.

Caldwell, C. H., Sellers, R. M., Bernat, D. H., \& Zimmerman, M. A. (2004). Racial identity, parental support, and alcohol use in a sample of academically at-risk African American high school students. American Journal of Community Psychology, 34, 71-82.

Caldwell, C. H., Wright, J. C., Zimmerman, M. A., Walsemann, K. M., Williams, D., \& Isichei, P. A. (2004). Enhancing adolescent health behaviors through strengthening non-resident father-son relationships: A model for intervention with African American families. Health Education Research, 19, 644-656.

Caldwell, C. H., Zimmerman, M. A., \& Isichei, P. A. (2001). Forging collaborative partnerships to enhance family health: An assessment of strengths and challenges in conducting community-based research. Journal of Public Health Management and Practice, 7, 1-9.

Centers for Disease Control and Prevention (2006). Cases of HIV infection and AIDS in the United States, by race or ethnicity, 2000-2004. HIV or AIDS Surveillance Supplement Report, 12, 1-36.

Centers for Disease Control and Prevention (2008). Youth risk surveillance-United States 2007. Morbidity and Mortality Weekly Report, 57(SS-4). Retrieved July 9, 2009, from http://www.cdc.gov/HealthyYouth/yrbs/pdf/ yrbss2007_mmwr.pdf

Chou, C. P., Yang, D., \& Hser, Y. (2004). Piecewise growth curve modeling approach for longitudinal prevention study. Computational Statistics \& Data Analysis, 2, 213-225.

Cleveland, M. J., Gibbons, F. X., Gerrard, M., Pomery, E. A., \& Brody, G. H. (2005). The impact of parenting on risk cognitions and risk behavior: A study of mediation and moderation in a panel of African American adolescents. Child Development, 76, 900-916.

Colarossi, L. G. (2001). Adolescent gender differences in social support: Structure, function, and provider type. Social Work Research, 25, 233.

Crosby, R. A., DiClemente, R. J., Wingood, G. M., Cobb, B. K., Harrington, K., Davies, S. L., Hook, E. W., \& 
Oh, M. K. (2001). HIV or STD-protective benefits of living with mothers in perceived supportive families: A study of high-risk African American female teens. Preventive Medicine, 33, 175-178.

Crosby, R. A., DiClemente, R. J., Wingood, G. M., Lang, D., \& Harrington, K. F. (2003). Value of consistent condom use: A study of sexually transmitted disease prevention among African American adolescent females. American Journal of Public Health, 93, 901-902.

Deptula, D. P., Henry, D. B., \& Schoeny, M. E. (2010). How can parents make a difference? Longitudinal associations with adolescent sexual behavior. Journal of Family Psychology, 24, 731-739.

Derogatis, L. R., \& Spencer, P. M. (1982). Brief symptom inventory: Administration, scoring, and procedure manual. Baltimore, MD: Clinical Psychometric Research.

DiClemente, R. J., Wingood, G. M., Crosby, R., Sionean, C., Cobb, B. K., Harrington, K., et al. (2001). Parental monitoring: Association with adolescents' risk behaviors. Pediatrics, 107, 1363-1368.

Dilorio, C., McCarty, F., \& Denzmore, P. (2006). An exploration of Social Cognitive Theory mediators of father-son communication about sex. Journal of Pediatric Psychology, 31, 917-927.

Dittus, P. J., Jaccard, J., \& Gordon, V. V. (1997). The impact of African American fathers on adolescent sexual behavior. Journal of Youth and Adolescence, 26, 445465.

Donenberg, G. R., Paikoff, R., \& Pequegnat, W. (2006). Introduction to the special section on families, youth, and HIV: Family-based intervention studies. Journal of Pediatric Psychology, 31, 869-873.

Elkington, K. S., Teplin, L. A., Mericle, A. M., Welty, L. J., Romero, E. G., \& Abram, K. M. (2008). HIV or STI risk behaviors in delinquent youth with psychiatric disorders: A longitudinal study. Journal of the American Academy of Child and Adolescent Psychiatry, 47, 901-911.

Elkington, K. S., Bauermeister, J. A., \& Zimmerman, M. A. (2010a). Do parents and peers matter? A prospective socio-ecological examination of substance use and sexual risk among African American youth. Journal of Adolescence, 35, 1035-1047.

Elkington, K. S., Bauermeister, J. A., \& Zimmerman, M. A. (2010b). Psychological distress, substance use, and HIV or STI risk behaviors among youth. Journal of Youth and Adolescence, 39, 514-527.

Fergus, S., \& Zimmerman, M. (2005). Adolescent resilience: A framework for understanding healthy development in the face of risk. Annual Review of Public Health, 26, 399-419.

Fergus, S., Zimmerman, M., \& Caldwell, C. (2007). Sexual risk behavior in adolescence and young adulthood. American Journal of Public Health, 97, 1096-1101.

Fisher, H., Eke, A., Cance, J., Hawkins, S., \& Lam, W. (2008). Correlates of HIV-related risk behaviors in African American adolescents from substance-using families: Patterns of adolescent-level factors associated with sexual experience and substance use. Journal of Adolescent Health, 42, 161-169.

Forehand, R., Armistead, L., Long, N., Wyckoff, S. C., Kotchick, P. A., Whitaker, D., ... Miller, K. S. (2007). Efficacy of a parent-based sexual-risk prevention program for African American preadolescents: A randomized controlled trial. Archives of Pediatrics \& Adolescent Medicine, 161, 1123-1129.

Garmezy, N. (1991). Resiliency and vulnerability to adverse developmental outcomes associated with poverty. American Behavioral Scientist, 34, 416-430.

Gillmore, M. R., Chen, A. C., Haas, S. A., Kopak, A. M., \& Robillard, A. G. (2011). Do family and parenting factors in adolescence influence condom use in early adulthood in a multiethnic sample of young adults? Journal of Youth and Adolescence, 40, 1503-1518.

Graves, K. L., \& Leigh, B. C. (1995). The relationship of substance use to sexual activity among young adults in the United States. Family Planning Perspectives, 27, 18-22.

Guilamo-Ramos, V., Jaccard, J., Dittus, P., Bouris, A., Holloway, I., \& Casillas, E. (2007). Adolescent expectancies, parent-adolescent communication and intentions to have sexual intercourse among inner-city, middle school youth. Annals of Behavioral Medicine, 34, 56-66.

Hadley, W., Brown, L. K., Lescano, C. M., Kell, H., Spalding, K., DiClemente, R., \& Donenberg, G. (2009). Parent-adolescent sexual communication: Associations of condom use with condom discussions. AIDS $\mathcal{E}$ Behavior, 13, 997-1004.

Hair, E. C., Moore, K. A., Garrett, S. B., Ling, T., \& Cleveland, K. (2008). The continued importance of quality parent-adolescent relationships during late adolescence. Journal of Research on Adolescence, 18, 187-200.

Halpern, C. T., Joyner, K., Udry, J. R., \& Suchindran, C. (2000). Smart teens don't have sex (or kiss much either). Journal of Adolescent Health, 26, 213-225.

Haveman, R., \& Wolfe, B. (1994). Succeeding generations: On the effects of investments in children. New York, NY: Russell Sage Foundation.

Heaney, C. A., \& Israel, B. A. (2002). Social networks and social support. In K. Glanz, B. K. Rimer, \& F. M. Lewis (Eds.), Health behavior and health education: Theory and practice (3rd ed., pp. 185-209). San Francisco, CA: Jossey-Bass.

Henrich, C. C., Brookymeyer, K. A., Shrier, L. A., \& Shahar, G. (2006). Supportive relationships and sexual risk behavior in adolescence: An ecological-transactional approach. Journal of Pediatric Psychology, 31, 286-297.

Houck, C. D., Lescano, C. M., Brown, L. K., TolouShams, M., Thompson, J., DiClemente, R., et al. (2006). "Islands of Risk": Subgroups of adolescents at risk for HIV. Journal of Pediatric Psychology, 31, 619-629.

Humblet, O., Paul, C., \& Dickson, N. (2003). Core group evolution over time: High-risk sexual behavior in a birth cohort between sexual debut and age 26. Sexually Transmitted Diseases, 30, 818-824. 
Hutchinson, M. K., Jemmott, J. B., Jemmott, L. S., Braverman, P., \& Fong, G. T. (2003). The role of motherdaughter sexual risk communication in reducing sexual risk behaviors among urban adolescent females: A prospective study. Journal of Adolescent Health, 33, 98107.

Jaccard, J., Dittus, P. J., \& Gordon, V. V. (1996). Maternal correlates of adolescent sexual and contraceptive behavior. Family Planning Perspectives, 28, 159-165.

Joffe, A., \& Radius, S. (1993). Self-efficacy and intent to use condoms among entering college freshmen. Journal of Adolescent Health, 14, 262-268.

Kim, S., \& Brody, G. H. (2005). Longitudinal pathways to psychological adjustment among Black youth living in single-parent households. Journal of Family Psychology, 19, 305-313.

Lauritsen, J. L. (1994). Explaining race and gender differences in adolescent sexual behavior. Social Forces, 72, 859-883.

Lehrer, J. A., Shrier, L., Gormaker, S., \& Buka, S. (2006). Depressive symptoms as a longitudinal predictor of sexual risk behaviors among US middle and high school students. Pediatrics, 118, 189-200.

Lowry, R., Holtzman, D., Truman, B. I., Kann, L., Collins, J. L., \& Kolbe, L. J. (1994). Substance use and HIVrelated sexual behaviors among U.S. high school students: Are they related? American Journal of Public Health, 84, 1116-1120.

Luthar, S. S. (2003). Resilience and vulnerability: Adaptation in the context of childhood adversities. Cambridge, UK: Cambridge University Press.

Malow, R. M., Devieux, J. G., Jennings, T., Lucenko, B. A., \& Kalichman, S. C. (2001). Substance-abusing adolescents at varying levels of HIV risk: Psychosocial characteristics, drug use, and sexual behavior. Journal of Substance Abuse, 13, 103-117.

Marshall, K., Crepaz, N., \& O'Leary, A. (2010). A systematic review of evidence-based behavioral interventions for African American youth at risk for HIV/STI infection, 1988-2007. In D. H. McCree, K. T. Jones, \& A. O'Leary (Eds.), African Americans and HIV/AIDS: Understanding and addressing the epidemic (pp. 151-180). New York, NY: Springer.

McKay, M. M., Chasse, K. T., Palkoff, R., McKinney, L., Baptiste, D., Coleman, D., Madison, S., \& Bell, C. C. (2004). Family-level impact of the CHAMP Family Program: A community collaborative effort to support urban families and reduce youth HIV risk exposure. Family Process, 43, 79-93.

McLoyd, V. C. (1990). The impact of economic hardship on Black families and children: Psychological distress, parenting, and socioemotional development. Child Development, 61, 311-346.

McLoyd, V. C., Cauce, A. M., Takeuchi, D., \& Wilson, L. (2000). Marital processes and parental socialization in families of color: A decade review of research. Journal of Marriage and the Family, 62, 1070-1093.
Meschke, L. L., Bartholomae, S., \& Zentall, S. R. (2000). Adolescent sexuality and parent-adolescent processes: Promoting healthy teen choices. Family Relations, 49, 143-154.

Miller, K. S., Forehand, R., \& Kotchick, B. A. (1999). Adolescent sexual behavior in two ethnic minority samples: The role of family variables. Journal of Marriage and the Family, 61, 85-98.

Morrison, T. C., DiClemente, R. J., Wingood, G. M., \& Collins, C. (1998). Frequency of alcohol use and its association with STD or HIV: Related risk practices, attitudes and knowledge among an African American community-recruited sample. International Journal of STDs and AIDS, 9, 608-612.

Morrison-Beedy, D., Carey, M. P., Feng, C., \& Tu, X. M. (2008). Predicting sexual risk behaviors among adolescent and young women using a prospective diary method. Research in Nursing and Health, 31, 329-340.

Murry, V. M., Bynum, M. S., Brody, G. H., Willert, A., \& Stephens, D. (2001). African American single mothers and children in context: A review of studies on risk and resilience. Clinical Child and Family Psychology Review, 4, 133-155.

Nakao, K., \& Treas, J. (1994). Updating occupational prestige and socioeconomic scores: How the new measures measure up. Sociological Methodology, 24, 1-72.

National Center on Addiction and Substance Abuse at Columbia University (1999). Dangerous liaisons: Substance abuse and sex. New York, NY: CASA.

Newman, P. A., \& Zimmerman, M. A. (2000). Gender differences in HIV-related sexual risk behavior among urban African American youth: A multivariate approach. Aids Education and Prevention, 12, 308-325.

Norris, A. E., \& Ford, K. (1999). Sexual experiences and condom use of heterosexual, low-income African American and Hispanic youth practicing relative monogamy, serial monogamy, and nonmonogamy. Sexually Transmitted Diseases, 26, 17-25.

O'Donnell, B. L., O'Donnell, C. R., \& Stueve, A. (2001). Early sexual initiation and subsequent sex-related risks among urban minority youth: The reach for health study. Family Planning Perspectives, 33, 268-275.

Perkins, D. F., Luster, T., Villaruel, F. A., \& Small, S. (1998). An ecological risk-factor examination of adolescents' sexual activity in three ethnic groups. Journal of Marriage and the Family, 60, 660-673.

Perrino, T., Gonzalez-Soldevilla, A., Pantin, H., \& Szapocznik, J. (2000). The role of families in adolescent HIV prevention: A review. Clincial Child and Family Psychology Review, 3, 81-96.

Peterson, S. H. (2007). The importance of fathers. Journal of Human Behavior in the Social Environment, 15, 329346.

Poulin, C., \& Graham, L. (2001). The association between substance use, unplanned sexual intercourse and other sexual behaviours among adolescent students. Addiction, 96, 607-621. 
Procidano, M. E., \& Heller, K. (1983). Measures of perceived social support from friends and from family: Three validation studies. American Journal of Community Psychology, 11, 1-24.

Rai, A. A., Stanton, B., Wu, Y., Li, X., Galbraith, J., Cottrell, L., ... Burns, J. (2003). Relative influences of perceived parental monitoring and perceived peer involvement on adolescent risk behaviors: An analysis of six cross-sectional data sets. Journal of Adolescent Health, 33, 108-118.

Raudenbush, S., \& Bryk, A. (2002). Hierarchical linear models: Applications and data analysis models (2nd ed.). Thousand Oaks, CA: Sage Publications.

Repetti, R. L., Taylor, S. E., \& Seeman, T. E. (2002). Risky families: Family social environments and the mental and physical health of offspring. Psychological Bulletin, 128, 330-366.

Rodgers, K. B. (1999). Parenting processes related to sexual risk-taking behaviors of adolescent males and females. Journal of Marriage and the Family, 61, 99-109.

Rutter, M. (1987). Psychosocial resilience and protective mechanisms. American Journal of Orthopsychiatry, 57, 316-331.

Rosenthal, S. L., Lewis, L. M., \& Cohen, S. S. (1996). Issues related to the sexual decision-making of innercity adolescent girls. Adolescence, 31, 731-739.

Salazar, L. F., Crosby, R. A., DiClemente, R. J., Wingood, G. M., Lescano, C. M., Brown, L. K., et al. (2005). Selfesteem and theoretical mediators of safer sex among African American female adolescents: Implications for sexual risk reduction interventions. Health Education $\mathcal{E}$ Behavior, 32, 413-427.

Salazar, L., DiClemente, R., Wingood, G. M., Crosby, R., Harrington, K., Davies, S., et al. (2004). Self-concept and adolescents' refusal of unprotected sex: A test of mediating mechanisms among African American girls. Prevention Science, 5, 137-149.

Salem, D. A., Zimmerman, M. A., \& Notaro, P. C. (1998). Effects of family structure, family process, and father involvement on psychosocial outcomes among African American adolescents. Family Relations, 47, 331-341.

Seth, P., Raiji, P. T., DiClemente, R. J., Wingood, G. M., \& Rose, E. (2009). Psychological distress as a correlate of a biologically confirmed STI, risky sexual practices, self-efficacy and communication with male sex partners in African-American female adolescents. Psychology, Health \& Medicine, 14, 291-300.

Shrier, L. A., Emans, J., Woods, E. R., \& Durant, R. H. (1997). The association of sexual risk behaviors and problem drug behaviors in high school students. Journal of Adolescent Health, 20, 377-383.

Shrier, L. A., Harris, S. K., \& Beardslee, W. R. (2002). Temporal associations between depressive symptoms and self-reported sexually transmitted disease among adolescents. Archives of Pediatrics \& Adolescent Medicine, 156, 599-606.

Shrier, L. A., Harris, S. K., Sternberg, M., \& Beardslee, W. R. (2001). Associations of depression, self-esteem, and substance use with sexual risk among adolescents. Preventive Medicine, 33, 179-189.

St. Lawrence, J. S., Brasfield, T., Jefferson, K., Alleyene, K., \& Shirley, A. (1994). Social support as a factor in African American adolescents' sexual activity. Journal of Adolescent Research, 9, 292-310.

SSI (2005). Hierarchical linear models. Chicago, IL: SSI Inc.

Staff, J., Schulenberg, J. E., Maslowsky, J., Bachman, J. G., O'Malley, P. M., Maggs, J. L., \& Johnston, L. D. (2010). Substance use changes and social role transitions: Proximal developmental effects on ongoing trajectories from late adolescence through early adulthood. Development and Psychopathology, 22, 917-932.

Stiffman, A. R., Dore, P., Earls, F., \& Cunningham, R. (1992). The influence of mental health problems on AIDS-related risk behaviors in young adults. Journal of Nervous and Mental Disease, 180, 314-320.

Tapert, S. F., Aarons, G. A., Sedlar, G. R., \& Brown, S. A. (2001). Adolescent substance use and sexual risk-taking behavior. Journal of Adolescent Health, 28, 181-189.

Taradash, A., Connolly, J., Pepler, D., Craig, W., \& Costa, M. (2001). The interpersonal context of romantic autonomy in adolescence. Journal of Adolescent, 24, 365-377.

Taris, T. W., \& Semin, G. R. (1997). Parent-child interaction during adolescence, and the adolescent's sexual experience: Control, closeness, and conflict. Journal of Youth and Adolescence, 26, 373-398.

Testa, M., \& Collins, R. L. (1997). Alcohol and risky sexual behavior: Event-based analyses among a sample of high-risk women. Psychology of Addictive Behaviors, 11, 190-201.

Thorburn, S., Harvey, S. M., \& Ryan, E. A. (2005). HIV prevention heuristics and condom use among African Americans at risk for HIV. Aids Care; Psychological and Socio-Medical Aspects of AIDS/HIV, 17, 335-344.

Tolou-Shams, M., Paikoff, R., McKirnan, D. J., \& Holmbeck, G. N. (2007). Mental health and HIV risk among African American adolescents. Social Work in Mental Health, 5, 27-58.

Tourangeau, R., Rips, L. J., \& Rabinski, K. (2000). The psychology of survey response. Cambridge, UK: Cambridge University Press.

Weinstein, M., \& Thornton, A. (1989). Mother-child relations and adolescent sexual attitudes and behavior. Demography, 26, 563-577.

Whitaker, D. J., \& Miller, K. S. (2000). Parent-adolescent discussions about sex and condoms: Impact on peer influences of sexual risk behavior. Journal of Adolescent Research, 15, 251-273.

Wills, T. A., Gibbons, F. X., Gerrard, M., Murry, V. M., \& Brody, G. H. (2003). Family communication and religiosity related to substance use and sexual behavior in early adolescence: A test for pathways through selfcontrol and prototype perceptions. Psychology of Addictive Behaviors, 17, 312-323.

Wills, T. A., Murry, V. M., Brody, G. H., Gibbons, F. X., Gerrard, M., Walker, C., \& Ainette, M. G. (2007). Ethnic pride and self-control related to protective and risk 
factors: Test of the theoretical model for the strong African American families program. Health Psychology, $26,50-59$.

Wingood, G. M., \& DiClemente, R. J. (1996). HIV sexual risk reduction interventions for women: A review. American Journal of Preventive Medicine, 12, 209217.

Wingood, G. M., \& DiClemente, R. J. (1998). The influence of psychosocial factors, alcohol, drug use on African American women's high-risk sexual behavior. American Journal of Preventive Medicine, 15, 54-59.

Zimmerman, M. A., Caldwell, C. H., \& Bernat, D. H. (2002). Discrepancy between self-report and school record GPA: Correlates with psychosocial outcomes among African American adolescents. Journal of Applied Social Psychology, 31, 86-109.
Zimmerman, M. A., Salem, D. A., \& Maton, K. I. (1995). Family structure and psychosocial correlates among urban African American adolescent males. Child Development, 66, 1598-1613.

Zimmerman, M. A., Salem, D. A., \& Notaro, P. C. (2000). Make room for daddy II: The positive effects of fathers' role in adolescent development. In R. D. Taylor \& M. C. Wang (Eds.), Resilience across contexts: Family, work, culture, and community (pp. 233-253). Mahwah, NJ: Lawrence Erlbaum Associates.

Zimmerman, M. A., Steinman, K. J., \& Rowe, K. J. (1998). Violence among urban African American adolescents: The protective effects of parental support. In X. B. Arriaga \& S. Oskamp (Eds.), Addressing community problems: Psychological research and interventions (pp. 78103). Thousand Oaks, CA: Sage. 